\title{
Application of Various Primary Tillage Systems in Western Siberia
}

\author{
Shahova Olga \\ Department of Farming, Agrotechnological Institute \\ Federal State Budgetary Educational \\ Institution of Higher Education \\ «Northern Trans-Ural State Agricultural University» \\ Tyumen, Russia \\ olshakhova@rambler.ru
}

\author{
Fisunov Nikolay \\ Department of Farming, Agrotechnological Institute \\ Federal State Budgetary Educational \\ Institution of Higher Education \\ «Northern Trans-Ural State Agricultural University» \\ Tyumen, Russia \\ fisunov1963@mail.ru
}

\begin{abstract}
Modern agriculture in Western Siberia requires a scientifically justified approach to selection of soil treatment method. Switching to new soil treatment methods without considerations for soil and climate features of the region leads to unpredicted results and reduced crop yields. The research objective is to study the primary tillage systems in Western Siberia. The experiments were conducted at the research station of the Northern Trans-Urals State Agricultural University, located in the northern forest-steppe of Tyumen oblast. The studied methods included moldboard plowing, non-moldboard loosening and a No-till technology as applied to spring wheat plots. It has been established, that on average the wheat yields amounted to $3.54 \mathrm{t} / \mathrm{ha}$ for the 5 years of research. Under the nonmoldboard loosening at $20-22 \mathrm{~cm}$, the grain yield reduced by $12 \%$ as compared to the plowed patch. Use of No-till technology in Western Siberia led to an abrupt drop in spring wheat yield. One of the causes leading to lower grain yields is weed infestation of the fields. Under plowing, the number of weeds and their relative share in the agrophytocenosis is minimal. Abandoning crop rotation led to increased weed infestation, despite chemical weeding. In the patch under No-till, the weight of weeds amounted to $1.62 \mathrm{t} /$ ha before the wheat harvest, which is $19 \%$ of agrophytocenosis; for the plowed batch, this value was $12 \%$. The research has found that No-till technology is unsuitable for Western Siberia.
\end{abstract}

Keywords- farming, plowing, No-till, weed ratio, agrophytocenosis.

\section{INTRODUCTION}

One of the main element in the agricultural system is a mechanical soil treatment. Its special role is in improvement of the foundations of the modern technologies of crop cultivation. Mechanical treatment methods directly influence agrophysical, physical, chemical and hydrochemical properties of agricultural soils. In combination with agricultural chemicals, they improve nutrition status and biological properties of soils. Despite a large number of studies, not all aspects of the scientifically-founded agricultural systems are equally well-developed. There is a need to refine the values describing an influence that a soil treatment method has onto soil fertility, phytosanitary status and biological activity of the plowed land. It is especially important for the regions of Russia with relatively recent agricultural development.
Western Siberia is rightly considered an area of risk farming. Harsh climate, short vegetation period and low fertility of soils impeded active development of agriculture here. Currently, thanks to scientific developments in farming, agrochemistry, reclamation and crop research, Western Siberia is considered a prospective agricultural zone [1-5]. Creation and modernization of soil-treatment machinery allowed for mechanical treatment of fields to be completed in short term and in a minimal number of passes [6]. Development of IT and its introduction in agriculture provides control over fields in real-time and allows for maximum efficiency from using both the natural factors and scientific developments [7].

New soil treatment technologies that has shown good results in the European part of Russia and abroad shall undergo thorough testing and scientific study for application in Western Siberia. Their cut-and-paste application without regard for features of soil and climate in the region may lead to the opposite results and have negative impact not only on the economic component of the agroindustrial complex, but on food security of the country as well. It is especially true of the No-till technology, which is while new for Western Siberia, has shown positive results in warm and relatively dry regions.

In the forest-steppe zone of Western Siberia, some problems impede distribution of technologies based on minimizing soil treatment. When using direct seeding for a prolonged period, agrophysical, agrochemical and biological properties undergo differentiation along the profile; this fact has been many times confirmed by both Russian and foreign researchers. Under the No-till technology, plant residue and nutrients are largely accumulated on the surface. Activity of microorganisms in the topsoil increases significantly, but is almost stopped in deeper layers due to a deficiency of the plant residue.

As N.V. Perfilyev, one of the leading specialists in resource-saving soil treatment in Western Siberia, noted, Notill is not a simplified technology, it is a movement to more intensive agrotechnologies. It requires a technological modernization of farming.

Research objective: Studying formation of spring wheat yields and infestation of fields with weeds depending on 
application of various types of primary tillage in Western Siberia.

\section{SUBJECTS AND METHODS}

The research has been conducted at the station of the Department of Farming, Northern Trans-Ural State Agricultural University, located at the eastern outskirts of Trans-Ural plateau, in the northern forest-steppe region of Tyumen oblast. The station is located several kilometers from the village of Uteshevo, Tyumen oblast; its coordinates are $\mathrm{N}$ 57009'30': E 65020'00'". The soil at the experimental plot is leached chenrozem (Voronic Chernozems WRB, 2016), shallow, black, heavy loamy, formed on carbonate clay loam mantle. The experiment design included 3 variants:

1. Moldboard treatment, plowing to a depth of $20-22 \mathrm{~cm}$ with a single-furrow plow - control;

2. Non-moldboard loosening to a depth of 20-22 cm with a noninversing plow developed by Siberian ElectroMechanical Plant (Omsk, Russia);

\section{No-till. Direct sowing with a mulch planter.}

Plowing and non-moldboard loosening were performed in the autumn, after harvesting the forecrop. In the spring, when structure-forming moisture content was attained, harrowing and cultivation were performed to a depth of $8-10 \mathrm{~cm}$. Before sowing, fertilizers were introduced, dosed for a planned harvest of $3.5 \mathrm{t} /$ ha of spring wheat grain. The grain crops were sowed in the third decade of May with subsequent rolling down.

During the tillering period, several patches of $1 \mathrm{~m} 2$ each were fixed for weed infestation studies (quantitative analysis and species composition). One month after chemical weeding, the surviving weeds were analyzed. Before the harvest, wheat was removed from the fixed patches and weeds were accounted for by a quantitative weight method. Weed ratio in the agrophytocenosis was calculated by determining the percentage ratio of the dried weight of weeds to the total biomass. ANOVA was used for statistical processing of the results.

\section{RESULTS}

During the period from 2013 to 2017, the yield of spring wheat in the variant with the moldboard plowing system amounted to $3.54 \mathrm{t} / \mathrm{ha}$, which is typical for the forest-steppe zone of Trans-Ural (Fig. 1). Achieving higher grain crop yields is possible in Western Siberia; however, it requires higher doses of mineral fertilizers [8]. Switching to nonmoldboard system of primary tillage promoted a $12 \%$ decrease in grain crop yield as compared to the variant that used plowing. During the years of research, average yield of spring wheat amounted to $3.12 \mathrm{t} / \mathrm{ha}$, which is 0.42 less than the previous variant.

Reduced yield when abandoning plowing for nonmoldboard loosening to a depth of $20-22 \mathrm{~cm}$ is due to a worsening temperature regime of the soil and deterioration of agrophysical indicators of the plowing horizon [13, 14]. Another very important cause for reduction of grain yields in fields where non-moldboard technologies are applied is an increased infestation with weeds. As researchers note, lack of soil turnover leads to accumulation of weed seeds in the $0-10$ $\mathrm{cm}$ layer. Deep loosening promotes undercutting suckers of perennial weeds, thus provoking their growth $[9,10]$.

Abandonment of mechanical soil treatment for direct

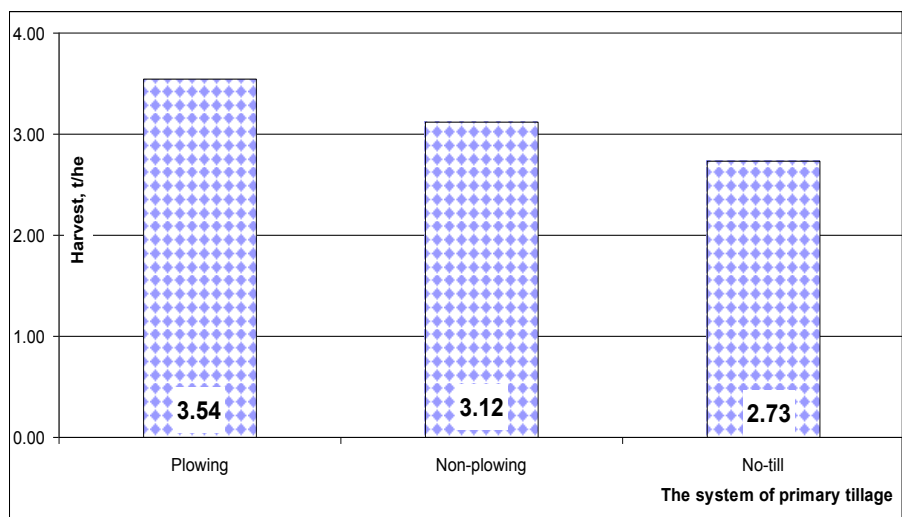

Fig. 1. Spring wheat yield when using various systems of primary tillage (2013-2017), t/ha

sowing in conditions of Western Siberia led to a sharp drop in grain crop yields. On average, it amounted to $2.73 \mathrm{t} / \mathrm{ha}$ for the period of research, which is $23 \%$ lower than the yield in the control plot (moldboard soil treatment). For the No-till system, the shortage of grain per hectare amounted to $0.81 \mathrm{t} / \mathrm{ha}$, which is very critical for the conditions of Western Siberia. A difference between the non-moldboard loosening and No-till was due to the fact that the soil gradually compacts, as the root system of grain crops does not have the loosening effect that is a feature of perennial herbs [11]. A deficiency of plan residues in the plowing layer leads to a deterioration of the humus status and has a negative influence onto agrophysical and hydrophysical properties of the soil [12]. Regional features of the soils of Western Siberia shall be taken into account; those features are unstable nutrition regime and low nitrification ability, both having negative impact onto the crop yields.

Selection of the primary tillage system determines subsequent changes in the process. It leads to changing conditions and, as a result, substitution of agrophytocenosis components.

The number of weeds largely depends on the soil treatment technology. There are a lot of data on this question, but they are very contradictory. Some researchers prove that weed infestation increases and crop yields decrease when switching from the moldboard plowing to a non-moldboard technology. Another group of scientists are pointing to advantages of blade cultivation and No-till, arguing that they allow decreasing weed infestation as all the weed seeds are in the top layer of the plowing horizon.

In the fields of Western Siberia one may find about 300 species of weeds. They dry the land, consume the nutrients and overshadow the crops. Economically significant losses start from 25 weed specimens per 1 square meter. Reduction in grain yield may reach $10 \%$. 
In the variant with the moldboard plowing, the number of weeds during the tillering period amounted to 47.9 specimen $/ \mathrm{m}^{2}$, which corresponded to a medium weed infestation (Fig. 2). Dominating species were early spring weeds: Fumaria officinalis (L.); Chenopodium album (L.); Galium aparine (L.). In the plowed field, there were also some late spring plants, like Echinochloa crusgali (L.) and Amaranthus retroflexus (L.).

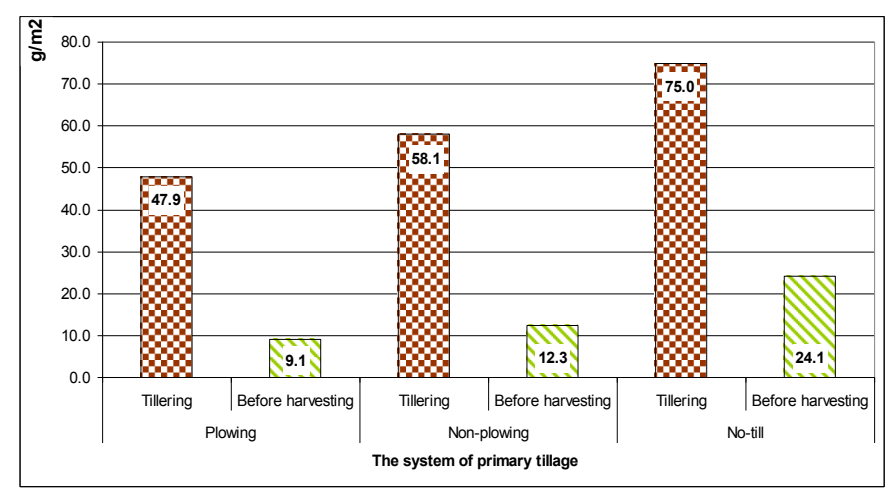

Fig.2. Influence of the primary tillage system onto weed infestation of spring wheat fields (2013-2017), specimen $/ \mathrm{m}^{2}$

The most harmful weeds were registered in single occurrences: Avena fatua (L.); Cirsium arvense (L.). During the research years, chemical weeding killed $87-95 \%$ of the total number of weeds. During the vegetation period, gradual appearance of late spring and fall-seeded weeds was observed. On average, their number did not exceed $10 \mathrm{specimen} / \mathrm{m}^{2}$ at the wheat harvesting time. It corresponds to a low degree of weed infestation. There were also registered individual specimens of perennial weeds: (Cirsium arvense (L.); Glechoma hederacea (L.); Sonchus arvensis (L.). However, their harmful effect was minimal, as they take up the lower level of the phytocenosis.

Where there is no soil layer rotation, non-perennial weeds experience advantageous conditions. Their seeds get to the soil surface and are partially covered with soil during the loosening. Under humid conditions of Western Siberia, it stimulates sprouting and increases weed infestation of the grain fields. During 2013-2017, on average, there were 58 specimens of weeds per 1 square meter during the tillering period, which corresponds to a medium degree of weed infestation. In comparison to control (plowing), the weed infestation increased by $21 \%$, thus, inevitably requiring a chemical weeding. The same species as in the control field were found in the weed infestation component here. However, their ratio was somewhat different. The dominating weeds here were: Galium aparine (L.) and Avena fatua (L.). There were more perennial weeds as well: Cirsium arvense (L.); Glechoma hederacea (L.); Sonchus arvensis (L.). Increased number of perennial weeds during the tillering of the spring wheat is because cutting a sucker wakes the sleeping buds and several plants appear at the surface. The mechanism of increasing the number of non-perennial weeds is determined by creation of advantageous conditions (humidity, aeration, good warming during the spring period) due to application of non-moldboard soil treatment technology in the conditions of Western Siberia. After chemical weeding, about $95-98 \%$ of germinated weeds died. However, by the time of harvest, the number of weed plants reached 12.3 specimen $/ \mathrm{m} 2$, which is $35 \%$ higher that the value in the annually plowed plot. This is explained by new plants appearing from the seeds in the top layer of the soil instead of the killed plants. As these seeds were in less heated layer of soil, their germination process was protracted and non-perennial weeds did not reach the surface by the time of the chemical weeding. A recovery mechanism of perennial weeds is similar: the plants that grew from the sucker roots being cut from the main root mass and reached the surface were killed out with the herbicide. However, mechanical damage provokes growth of new plants from the sleeping buds of those suckers, which lay deeper than the loosening zone of the non-moldboard tool. These plants appear on the surface significantly later, after the completion of the chemical weeding. During this period, the weather condition in Western Siberia are usually beneficial for perennial weeds, as the soil is warmed and watered. Application of herbicides during the later periods is virtually impossible, as grains in paniculation stage become susceptible to chemicals. In the end, the Western Siberian fields under non-moldboard system of soil treatment have a significantly higher level of weed infestation, while grain yield is decreased in comparison to plowing.

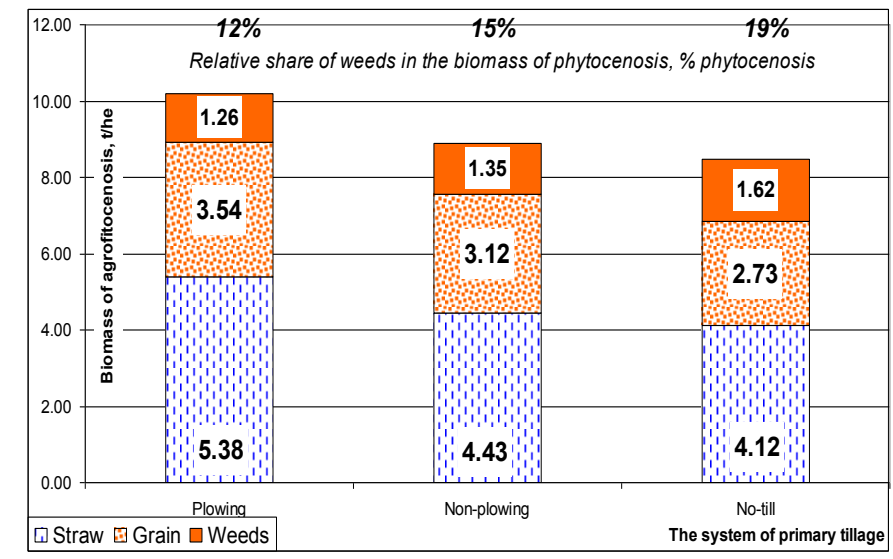

Fig. 3. Biomass of the grain agrophytocenosis ( $t / h a)$ and percentage of weeds in it when using various systems of primary tillage (2013-2017)

Switching to No-till leads to a serious increase in weed infestation of the grain crop fields. During the tillering period, the number of weed plants as averaged for 5 years of studies amounted to 75 specimen $/ \mathrm{m} 2$, corresponding to a high degree of weed infestation. The same species as in the previously considered variants were found in the weed infestation component here, however, their ratio was somewhat different. An increased share of perennial weeds should be noted, while annual weeds still dominate. In the spring, wheat fields cultivated under the No-till technology there were a large number of Avena Fatua (L.). A sharp increase in weed infestation in the fields under No-till is due to the fact that in dense soil, the suckers of Cirsium arvense (L.) and Sonchus arvensis (L.) form a larger number of sleeping buds that wake up gradually and start new plants throughout the vegetation period. Before the harvest, the fields under the No-till technology had the maximum number of weed plants at 24.1 
specimen $/ \mathrm{m} 2$, which is almost three times higher than in the control (plowed) field. It should be noted, that unlike previous variants, weeds in the No-till fields did not just take up the lower levels of the agrophytocenosis, but stood high over the spring wheat, depressing it. Application of additional chemical weeding in grain crop fields is unacceptable in Western Siberia, as it leads to a sharp decrease in yield. There are several workarounds for this situation. One may select such preparations from a wide range of available herbicides that have prolonged effect and are soil-linked agricultural chemicals. Another way is more environmentally friendly and is based on the ability of cultivated plants to suppress weeds. It would require locally selected varieties with high ecological plasticity and fast development in the early vegetation period $[15,16]$. Development of a regional system for fertilizing the grain crops will allow providing fast consumption of nutrients in the first half of the summer, thus preventing the development of the weed component.

The system that is common in Western Siberia has been developed for fast warming of soil and to improve its agrophysical and hydrophysical properties. In the spring, during the planting season, optimal conditions are formed for emergence of seedlings and formation of a strong root system. In the end, biomass of the cultivated plants amounts to 8.9 $\mathrm{t} / \mathrm{ha}$, which is 7 times larger than the mass of weeds appearing after the chemical weeding (Fig. 3). Relative share of the weed component amounts to $12 \%$ of the wheat agrophytocenosis, which is quite high. It may be considered a regional feature of Western Siberian fields. This value may be lowered only by a systematic removal of the weed seeds from the plowing layer.

In the plot under non-moldboard at a depth of 20-22 cm, the biomass of spring wheat (straw + grain) amounted to 7.55 $\mathrm{t} / \mathrm{ha}$, which is $18 \%$ lower than the values obtained under plowing. The relative share of weeds increased to $15 \%$ of the phytocenosis mass under the non-moldboard treatment. It points to the fact that spring wheat is less sturdy at the nonmoldboarded background and cannot resist against the weeds. Thus, a certain alternation of non-moldboard loosening with plowing is necessary to keep the field relatively free of weeds.

Of the most interest in the No-till variant, where the relative share of weeds in the agrophytocenosis is maximal and reaches $19 \%$ of biomass. It should be noted straight away, that the same protection system was used against pests, plant diseases and weeds in all the studied variants; thus, sturdiness of the spring wheat was formed only by means of soil conditions due to different soil treatment methods. In Western Siberia, No-till cannot provide grain crops with beneficial conditions, thus they cannot compete against the weeds appearing after the chemical weeding is complete. Biomass of the spring wheat in this variant was on average $6.85 \mathrm{t} / \mathrm{ha}$ during the years of the studies, which is the minimum value. Dry weight of weeds during harvest reached $1.62 \mathrm{t} / \mathrm{ha}$, which is $30 \%$ higher than the control values obtained on plowed soil. The relative share of weeds in the wheat agrophytocenosis $(19 \%)$ corresponded to a medium degree of weed infestation in the end of the vegetation period. In other variants, the weed infestation corresponded to a low level. This is an evidence, that in Western Siberia switching to No-till provokes an uncontrollable weed infestation of fields and reduces productivity.

\section{CONCLUSION}

A wide application of modern energy-saving methods of the primary tillage is proposed with the aim of recovery and preservation of soil fertility in Western Siberia and provision of sustainable high productivity of plowed land while reducing material and technical costs for the main treatment when cultivating crops. Reduction of weed infestation of fields would require developing a scientifically justified system of plant protection that takes into account soil and climate features of the region.

In the forest-steppe zone of Western Siberia, the most advantageous is the moldboard system of the primary tillage, which provides stable yields of wheat up to $3.5 \mathrm{t} / \mathrm{ha}$. Switching to non-moldboard loosening reduces grain yield per hectare by $12 \%$, compared to the moldboard plowing. A complete abandonment of mechanical treatment (the No-till technology) has a negative influence onto grain crop yields, which are reduced by $23 \%$ compared to plowed land. Annual moldboard plowing keeps the spring wheat fields relatively free of weeds and facilitates competitive nature of the cultivated plants in the argophytocenoses. Under non-moldboard loosening, the relative share of weeds in the agrophytocenosis increases to $15 \%$, while under plow it is $12 \%$. Switching to No-till leads to a significant increase in infestation of fields with Avena Fatua, Cirsium arvense and Sonchus arvensis, despite application of modern herbicides. In Western Siberia, abandonment of the mechanical soil treatment creates disadvantageous conditions for growth and development of grain crops that cannot compete against the weeds appearing in the second half of the vegetation period.

\section{References}

[1] D.I. Eremin, "The use of modern data about the composition and properties of soil for the development of transport infrastructure of Tyumen", IOP Conference Series: Earth and Environmental Science, 2017, V. 90, Conf. 1. DOI: org/10.1088/1755-1315/90/1/012021.

[2] D.T. Degefie, E. Fleischer, O. Klemm, A.V. Soromotin, O.V. Soromotina, A.V.Tolstikov and N.V. Abramov, "Climate extremes in south western Siberia: past and future" Stoch. Environ. Res. Risk Assess, no. 28, 2014, pp. 2161-2173. DOI: 10.1007/s00477-014-08729.

[3] D. Eremina, "The impact of transport infrastructure on ecological status of arable land in Western Siberia," MATEC Web of Conferences, 170, 2018, pp. 05004. DOI: https://doi.org/10.1051/matecconf/201817005004

[4] A.V. Iglovikov, "The development of artificial Phytocenosis in Environmental Construction in the far North", Procedia Engineering, no. 165, 2016, pp. 800-805. DOI:10.1016/j.proeng.2016.11.778.

[5] I. Kuhling, D. Redozubov, G. Broll and D. Trautz, "Impact of tillage, seeding rate and seeding depth on soil moisture and dryland spring wheat yield in Western Siberia", Soil \& Tillage Research, 2017, no. 170, pp. 43-52. DOI: 10.1016/j.still.2017.02.009

[6] N. Ustinov, A. Maratkanov and A. Martynenko, "Experimental study of the parameters of the active tool of a cultivator with a frame in form a flexible tubular element", MATEC Web of Conferences, no. 106, 2017, pp. 08063. DOI: https://doi.org/10.1051/matecconf/201710608063

[7] D. Eremina, "IT-technologies in soil Informatics and Russian agribusiness", [MATEC Web of Conferences. no. 170, 2018, pp. 04016. DOI: https://doi.org/10.1051/matecconf/201817004016] 
[8] D.I. Eremin and N. A. Gruzdeva, “ Influence of anthropogenic factor on microaggregate composition of gray forest soils", Siberian Bulletin of agricultural science, no. 1, 2018, pp. 28-37. DOI: 10.26898/0370-8799. 2018-1-4

[9] K.S. Gill and M.A. Arshad, "Weed flora in the early growth period of spring crops under conventional, reduced and zero tillage systems on a clay soil in northern Alberta, Canada", Soil \& Tillage Res., no. 33, 1995, pp. $65-79$.

[10] S. Borstlap and M. Entz, "Zero-tillage influence on canola, field pea and wheat in a dry sub-humid region: agronomic and physiological responses" Can. J. Plant Sci., no. 3, 1994, pp.411-420.

[11] J. Lipecki and S. Berbec, "Soil management in perennial crops: orchards and hop gardens", Soil\&tillage research., no. 1-2, 1997, pp. 169-184

[12] D.I. Eremin, "Changes in the content and quality of humus in leached chernozems of the Trans-Ural forest-steppe zone under the impact of their agricultural use", Eurasian soil science, 2016, no. 5, pp. 538-545. DOI: $10.1134 / \mathrm{S} 1064229316050033$
[13] E.V. Shein and O.A. Troshina, "Physical properties of soils and the simulation of the hydrothermal regime for the complex soil cover of the Vladimir Opol'e region", Eurasian Soil Sci., no. 45, 2012, pp. 968-976. DOI: $10.1134 / \mathrm{S} 1064229312100092$

[14] D.I. Eremin, "Soils swelling as a regional feature of Western Siberia," [MATEC Web of Conferences, no. 170, pp. 02017 https://doi.org/10.1051/matecconf/201817002017]

[15] A. Lyubimova and D. Eremin, "Laboratory varietal control as a guarantee of successful work of agribusiness in Russia”, [MATEC Web of Conferences, no. 170, 2018, pp. 04015 . https://doi.org/10.1051/matecconf/201817004015]

[16] Y.P. Loginov, A.A. Kazak, L.I. Yakubyshina, T.N. Falaleeva, S.N. Yashchenko and E.T. Yarova, "Breeding value of collection varieties of potato in the forest-steppe zone of the Tyumen region", Journal of Pharmaceutical Sciences and Research., no. 1, 2018, pp. 377-380. 